\title{
A INTERFACE DOS DIREITOS LABORAIS E PREVIDENCIÁRIOS COM OS ACIDENTES DO TRABALHO NA SOCIEDADE CONTEMPORÂNEA
}

\author{
Antonio Donizetti de Resende* \\ André Geraldo Santos Cardoso de Mesquita**
}

\section{RESUMO}

A Constituição Federal de 1988 tem a dignidade da pessoa humana e os valores sociais do trabalho e da livre iniciativa como princípios. Destarte, como objetivo geral, estudou-se a legislação trabalhista e previdenciária atende aos citados comandos, contribuindo para a redução dos acidentes do trabalho. Averiguou-se, como objetivo específico, se os segurados previdenciários, acometidos por acidentes do trabalho, dispõem de adequada tutela dos seus direitos e interesses no arcabouço jurídico pátrio. As últimas estatísticas da Previdência Social registram uma redução dos benefícios e dos acidentes do trabalho, inclusive àqueles com óbitos, demonstrando eficácia normativa e gerencial.

Palavras-chave: acidentes; trabalho; previdência social; segurados; benefícios.

\section{THE LABOR AND SOCIAL SECURITY RIGHTS INTERFACE WITH INDUSTRIAL ACCIDENTS IN CONTEMPORARY SOCIETY}

\begin{abstract}
The Federal Constitution of 1988 has the dignity of the human person and the social values of labor and free enterprise principles. Thus, as a general objective, studied the labor and social security legislation meets the listed commands, contributing to the reduction of accidents at work. It was, as a specific objective, if the insured assets, affected by accidents at work, have adequate protection of their rights and interests in the legal framework of the homeland. The latest Social Security statistics show a reduction in benefits and accidents at work, including those with deaths, demonstrating normative and managerial effectiveness.
\end{abstract}

Keywords: accidents; work; social security; insured; benefits.

\section{INTRODUÇÃO}

No art. $1^{\circ}$ da CRFB/88 "Constituição da República Federativa do Brasil de 1988” encontra-se positivado os fundamentos da República brasileira, entre eles: a dignidade da pessoa humana e os valores sociais do trabalho e da livre-iniciativa. Esses princípios, embasam, não somente a legis lação constitucional, mas, todo o arcabouço jurídico do país. No entanto, alguns operadores e estudiosos do direito, têm criticado a Lei $\mathrm{n}^{\circ} 13.467 / 17$, que reformou a CLT “Consolidação da Leis do Trabalho" e, descumprindo estes e outros

\footnotetext{
* Mestrando em Direito - Universidade de Itaúna - e-mail: resende36@ yahoo.com.br.

** Mestrando em Direito - Universidade de Itaúna - e-mail: andregscmesquita@ hotmail.com.
}

Rev. do Dir. do Trabalho e Meio Ambiente do Trabalho | e-ISSN: 2525-9857 | Salvador | v. 4 | n. 1 | p. 77 - 
princípios constitucionais, retirou muitos direitos dos trabalhadores. Além destes complicadores, os obreiros, atualmente, convivem com altos índices de acidentes do trabalho. Tais fatos, induzem a um quantitativo de suspensão dos contratos laborais elevado e, consequentemente, do respectivo auxílio previdenciário.

Mas, resta saber se as vítimas dos acidentes do trabalho, têm ou não, os seus direitos constitucionais, laborais e previdenciários efetivamente resguardados; bem como, se o arcabouço jurídico pátrio é eficaz para tutelar e promover a redução destes acidentes.

Assim, esta pesquisa visa analisar se as normas trabalhistas e previdenciárias vigentes, efetivamente, tutelam e contribuem para a redução dos acidentes do trabalho no Brasil. Também será objeto de estudo, verificar quais trabalhadores são detentores desses direitos e qual é o meio de custeio do benefício acidentário. Sequencialmente, ainda será averiguado se o trabalhador, vítima do acidente do trabalho, poderá pleitear, simultaneamente, benefício previdenciário e possíveis danos patrimoniais, morais e lucro cessante, sofridos pelo mesmo.

Desse modo, após a compilação dos dados estudados, utilizando-se o método teórico bibliográfico-dedutivo, partindo-se de um posicionamento macroanalítico para outro microanalítico, buscar-se-á, responder os questionamentos supra.

Para isso, estudar-se-á sobre os aspectos jurídicos e fáticos que fundamentam os acidentes do trabalho e o respectivo benefício previdenciário no país. Analisando-se, sequencialmente: o SAT "seguro do acidente de trabalho"; a contribuição para a Seguridade Social; a contribuição para custeio do SAT/GILRAT "seguro de acidente do trabalho em função do grau de incidência de incapacidade laborativa decorrente dos riscos ambientais do trabalho"; a contribuição do FAP/GILRAT; "fator acidentário de prevenção em função do GILRAT"; caracterização e direitos decorrentes do acidente de trabalho. Finalmente, para possibilitar responder aos questionamentos supra, analisar-se-á sobre a situação dos acidentes do trabalho no brasil nos últimos anos.

\section{DIREITOS LABORAIS E PREVIDENCIÁRIOS}

Um dos marcos mais importantes do Direito Laboral brasileiro, ocorreu com a promulgação da CLT "Consolidação das Leis do Trabalho", em $1^{\circ}$ de maio de 1943 , pelo Decreto-Lei $n^{\circ}$ 5.452/43. Já, quanto à Lei 13.467 de 13 de julho de 2017, que reformou a 
CLT, não se pode dizer o mesmo. Tais alterações, são bastante questionadas por estudiosos e "operadores" do direito laboral. V. g., as efetuadas pela $2^{\text {a }}$ JDMPT "Segunda Jornada de Direito Material e Processual do Trabalho da ANAMATRA “Associação Nacional dos Magistrados do Trabalho". Muitos dos 125 (cento e vinte e cinco) EN “enunciados", do mencionado evento, criticam à Lei $\mathrm{n}^{\circ} 13.467 / 17$. O primeiro EN, aprovado pela $2^{\mathrm{a}} \mathrm{JDMPT}$, questiona a incompatibilidade vertical da referida legislação com as convenções internacionais - ratificadas pelo Brasil - convenções 144 e 154 da OIT "Organização Internacional do Trabalho". No segundo EN, atribui-se como autoritária e antirrepublicana toda ação política, midiática, administrativa ou correicional que pretender impor ao Juiz do Trabalho uma postura mecanicista, ou seja, obrigar o juiz interpretar a lei de modo exclusivamente literal e/ou gramatical. Assim, o EN n ${ }^{\circ} 2$ da $2^{\text {a }}$ JDMPT, funda-se no controle difuso de constitucionalidade e de convencionalidade e, assevera que todo magistrado deve cumprir e fazer cumprir tanto a Constituição quanto a legislação. (ANAMATRA, 2 $2^{\mathrm{a}}$ JDMPT, 2017).

$\mathrm{O} \mathrm{EN} \mathrm{n}^{\circ} 6$ da $2^{\mathrm{a}} \mathrm{JDMPT}$, considera a lei $\mathrm{n}^{\circ} 13.467 / 17$, ilegítima nos sentidos formal e material. $\mathrm{O} \mathrm{EN} \mathrm{n}^{\circ} 11$, questiona o art. 11, $\S 3^{\circ}$ da CLT (incluído pela Lei $\mathrm{n}^{\circ}$ 13.467/17), pois a interrupção da prescrição, por força do art. $8^{\circ}$ da CLT, deve observar também ao art. 205 do CC/02 “Código Civil de 2002”. O EN n 12, considera a prescrição total, prevista no art. $11, \S 2^{\circ}$ da CLT (incluído pela Lei $n^{\circ} 13.467 / 17$ ) inconstitucional, por ser incompatível

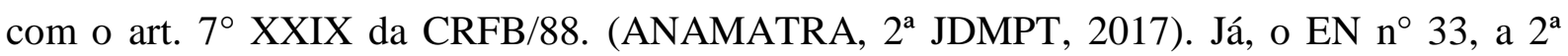
JDMPT, defende a impossibilidade de redução do enquadramento do grau de insalubridade, afirmando que:

\footnotetext{
Considerando o princípio da primazia da realidade, e sendo a saúde um direito de todos e dever do Estado, e considerando ainda a ilicitude da supressão ou redução dos direitos provenientes de normas de saúde, higiene e segurança do trabalho, prevalecerá o acordado sobre o legislado sempre que se tratar de pagamento de percentual superior àquele determinado na NR-15, não sendo possível a redução do referido adicional. (ANAMATRA, $\mathrm{EN} \mathrm{n}^{\circ} 33,2^{\mathrm{a}}$ JDMPT, 2017).
}

O excerto supra, questiona o art. 394-A da CLT, pois este artigo fere o direito fundamental constitucional a saúde, ao permitir o trabalho em ambiente insalubre - grau médio ou mínimo - para mulheres grávidas e lactantes. Além do retrocesso, é inconcebível o comprometimento da segurança e da saúde da trabalhadora gestante. (BRASIL. CLT, 2018). 


\section{ACIDENTE DO TRABALHO NO ORDENAMENTO JURÍDICO BRASILEIRO}

Os acidentes do trabalho são motivados, dentre outros motivos, pela desatenção, imprudência, desconhecimento técnico, não utilização dos equipamentos de proteção (individual e coletivo) e ainda pela falta de orientação e de fiscalização. Não há como tipificar taxativamente todos os tipos de acidentes do trabalho e, muito menos, os riscos de exposição aos mesmos. Assim, o rol dos acidentes do trabalho é exemplificativo, não se detalhou exaustivamente todas as hipóteses em que o exercício da atividade desempenhada pelo obreiro poderá incorrer em incapacidade laboral para o desempenho de sua atividade.

\subsection{Conceito e especificação do acidente de trabalho e do segurado da Previdência Social}

A lei definiu somente o acidente típico, mas, assegurou os mesmos direitos aos acidentes considerados por motivo de doença e os equiparados. Com isso, o caput do art. 19 da Lei $\mathrm{n}^{\circ}$ 8.213/91, conceituou o acidente de trabalho típico como: aquele acidente que provoque lesão corporal ou perturbação funcional que cause a morte ou mesmo a perda ou redução, permanente ou temporária, da capacidade laboral. Condiciona-se ainda que, tais acidentes, ocorram pelo exercício do trabalho - a serviço da empresa ou do empregador doméstico - ou dos segurados especiais.

No art. 20, caput, incisos I e II da Lei $n^{\circ} 8.213 / 91$ está regulamentado o acidente de trabalho por entidades mórbidas (por doença). Nestes termos, as entidades mórbidas são: I doença profissional - aquela produzida ou desencadeada pelo exercício do trabalho peculiar a determinada atividade (constante da listagem elaborada pelo Ministério do Trabalho e Previdência Social); II - doença do trabalho - aquela adquirida ou desencadeada em função de condições especiais em que o trabalho é realizado e com ele se relacione diretamente. Mas, apesar do acidente do trabalho se vincular às condições especiais de trabalho e não, especificamente, à atividade, esta deve constar da referida relação do Ministério do Trabalho e Previdência Social.

Porém, o mesmo art. 20, $\S \S 1^{\circ}$ e $2^{\circ}$ da Lei dos PBPS "Planos de Benefícios da Previdência Social", determina que não são consideradas como doença do trabalho: a) doença degenerativa; b) aquela inerente à grupo etário; a que não produza incapacidade degenerativa; c) doença endêmica adquirida por segurado habitante de região em que ela se desenvolva, 
salvo comprovação de que é resultante de exposição ou contato direto e determinado pela natureza do trabalho. Mas, excepcionalmente, constatando-se que a doença não consta na relação menciona supra, mas, é resultante das condições especiais em que o trabalho é executado e com ele se relaciona diretamente, a Previdência Social deve considerá-la como acidente do trabalho.

Os acidentes por equiparação estão tipificados no art. 21 da Lei $n^{\circ}$ 8.213/91, que são: a) aquele vinculado ao trabalho, que embora não tenha sido a única causa, mas contribuiu para ocorrência da morte ou redução da capacidade para o trabalho do segurado, ou ainda tenha produzido lesão que exija atenção médica para a sua recuperação; b) sofrido pelo segurado no local de trabalho e dentro do horário da prestação dos serviços, que seja motivado por ato de agressão, sabotagem ou terrorismo, praticado por terceiros ou outro colega de trabalho; c) gerado por ofensa física intencional, inclusive por pessoas estranhas ao serviço, mas por motivo de disputa relacionada ao trabalho; d) por ato de imprudência, de negligência ou de imperícia de terceiro ou de colega de trabalho; e) por ato de pessoa desequilibrada ou desorientada; f) por desabamento, inundação, incêndio e demais casos fortuitos ou de força maior; g) a doença oriunda de contaminação acidental do trabalhador empregado, durante o período de exercício de sua atividade; h) o acidente sofrido pelo segurado, mesmo que tenha ocorrido fora do local e do horário do trabalho, quando: na execução de ordem ou realizando serviços autorizados pela empresa; i) na realização de atividades laborais espontâneas de qualquer natureza para empresa; $\mathrm{j}$ ) durante viagem a serviço da empresa, inclusive quando estiver participando de estudos de capacitação e aprimoramento financiado pela mesma (independente do meio de transporte utilizado, inclusive veículo de propriedade particular do segurado) ou ainda, no percurso da residência para o local de trabalho ou vice-versa, (qualquer que seja o meio de locomoção, inclusive veículo de propriedade do segurado).

Nos períodos destinados ao intervalo para refeições ou descanso no local de trabalho ou durante o mesmo, o empregado deverá ser considerado como em efetivo exercício do trabalho. No entanto, não será computado como agravação ou complicação do acidente do trabalho, aquela lesão, que for derivada de origem diversa. Ou seja, nos casos em que se associar ou superpor às consequências de doenças ou eventos acidentários anteriores. Observe-se que, as doenças ocupacionais se diferem dos acidentes do trabalho em termos de caracterização, mas, para efeito dos benefícios previdenciários, ambas as modalidades são consideradas como acidentes de trabalho. 


\begin{abstract}
Inicialmente, é de se pontuar que os acidentes e doenças que aqui são abordados têm em comum o fato de serrem originados em um labor sob a forma de emprego, ou seja, daquele trabalho que se conforma nos elementos fáticos previstos nos arts. $2^{\circ} \mathrm{e}$ $3^{\circ}$ da Consolidação das Leis do Trabalho. O que não significa que o fato de aquele trabalho não ter merecido o reconhecimento formal da sua condição empregatícia afastará a configuração do acidente ou da doença como de trabalho. É que sempre haverá a possibilidade de se discutir, até incidentalmente, que o trabalho que originou o dano se deu sob a forma de emprego e não autônoma. [...]. Outro ponto importante a ser destacado é que a distinção doença ocupacional e acidente de trabalho se faz importante para efeito doutrinário, entretanto, em termos de proteção oriunda da legislação, não há qualquer diferença, pois acidente e doença são equiparados para fins e efeitos da referida proteção. (SENA, 2011, p. 678).
\end{abstract}

A NR-7 “Norma Regulamentadora $n^{\circ} 7$ ” da Portaria $n^{\circ} 3.214 / 78$, estabelece sobre as doenças ocupacionais, que são duas: doenças profissionais e doenças do trabalho. (BRASIL. NR-7, 2014, p. 85). Já, o Decreto n 3.048/99, relaciona-as em uma lista de mais de 200 (duzentas) doenças. Porém, este rol não é taxativo, outras doenças não constantes dessa lista, também poderão ser consideradas como doença profissional ou do trabalho, desde que comprovado o nexo causal e o devido enquadramento do vínculo exigido pela legislação. (RODRIGUES, 2014, p. 84). Portanto, para caracterizar um acidente do trabalho não basta comprová-lo, precisa-se demonstrar o nexo de causalidade, tanto na esfera administrativa quanto no Judiciário, nos casos litigiosos. O trabalhador necessita ser segurado da Previdência social. Estes segurados, se dividem em obrigatórios e facultativos. Os segurados obrigatórios estão previstos no art. 12 da Lei $n^{\circ} 8.212 / 91$, art. 11 da Lei $n^{\circ} 8.213 / 91$ e no art. $9^{\circ}$ do RPS "Regulamento da Previdência Social". Os segurados facultativos são aqueles excluídos ou não vinculados automaticamente ao RGPS "Regime Geral da previdência Social", exceto os filiados aos regimes próprios.

Esta possibilidade existe em relação a todas as pessoas que não são vinculadas automaticamente ao sistema previdenciário, ou seja, não exercem atividade remunerada que deflagre a filiação automática. Como possíveis facultativos, temos a dona de casa, o estagiário, o estudante etc. Alguns trabalhadores, apesar de exercerem atividade remunerada, são excluídos do RGPS expressamente. Isto ocorre quando estes indivíduos já possuem filiação a regime próprio de previdência, em razão da atividade remunerada que exercem, como servidores públicos federais e militares. (IBRAHIM, 2015, p. 211).

Conforme especificado, são considerados como segurados obrigatórios da Previdência Social (Lei $\mathrm{n}^{\circ}$ 8.213/91, art. 11) os empregados, incluindo os domésticos e avulsos; o especial e o contribuinte individual. Em princípio, a lei ao definir o acidente do 
trabalho, excluiu o contribuinte individual, pois, na sua definição de acidente do trabalho, só considerou os empregados e o segurado especial.

O segurado avulso (Lei $\mathrm{n}^{\circ}$ 8.213/91, art. 11, inciso VI) é aquele que presta serviços, urbanos ou rurais em mais de uma empresa sem vínculo empregatício. Já, o segurado especial, (Lei ${ }^{\circ}$ 8.213/91, art. 11, inciso VII), refere-se à pessoa física que - residente no imóvel rural ou em aglomerado urbano, próximo à área rural - labore individualmente ou em regime de economia familiar, ainda que tenha o auxílio eventual de terceiros. Os segurados especiais devem enquadrar-se em algumas condições: a) produtor - proprietário, usufrutuário, possuidor, assentado, parceiro ou meeiro outorgado e comodatário; arrendatário rural - desde que explore a atividade de agropecuária em área de até quatro módulos ficais; seringueiro ou extrativista vegetal - que exerça as suas atividades nos termos do art. $2^{\circ}$, inciso XII da Lei ${ }^{\circ}$ 9.985 de 18 de julho de 2000; b) pescador artesanal ou a este assemelhado - que faça da pesca sua profissão habitual ou principal meio de vida; c) cônjuge ou companheira, filho maior de dezesseis anos de idade ou a este equiparado, do segurado - de que tratam as alíneas "a" e "b" retrocitadas, e ainda que, comprovadamente, trabalhem com o grupo familiar respectivo.

A Lei $n^{\circ} 9.985 / 00$, que regulamentou o art. $225, \S 1^{\circ}$, incisos I, II, III e VII da CRFB/88 e instituiu o Sistema Nacional de Unidades de Conservação da Natureza, especifica que a profissão de extrativismo deverá ser exercida como um sistema de exploração sustentável, baseado na coleta e extração de recursos naturais renováveis.

\subsection{Seguro do Acidente de Trabalho - SAT}

Encontra-se positivado no art. $7^{\circ}$ caput, inciso XXVIII da CRFB/88 o seguro contra o acidente do trabalho: "são direitos dos trabalhadores urbanos e rurais, além de outros que visem à melhoria de sua condição social: seguro contra acidentes de trabalho, a cargo do empregador, sem excluir a indenização a que este está obrigado, quando incorrer em dolo ou culpa". Já, o artigo $7^{\circ}$, inciso XXXIV da Carta Política de 1988, estabeleceu a igualdade de direitos entre o trabalhador com vínculo empregatício permanente e o trabalhador avulso. Assim, o SAT/GILRAT (art. 22 da Lei 8.212/91) também abrange o trabalhador avulso. Com isso, o referido seguro foi garantido tanto aos segurados empregados, quanto aos segurados especiais, sejam eles urbanos ou rurais. 


\subsection{Contribuição para a Seguridade Social}

Em conformidade com o princípio da dignidade da pessoa humana e o princípio da solidariedade, o legislador constitucional, positivou nos art. 194 e 195 da Constituição Federal de 1988 o instituto que prevê a Seguridade Social e seus meios de financiamento. A Seguridade Social (art. 194, caput da CRFB/88) é constituída pelo conjunto integrado de ações de iniciativa dos poderes públicos e da sociedade, destinadas a assegurar os direitos à saúde, à previdência e à assistência social.

O financiamento da Seguridade Social é imputado a toda a sociedade de forma direta e indireta (art.195, caput da CRFB/88). Em atendimento aos comandos constitucionais, o art. 10 da Lei $\mathrm{n}^{\circ} 8.212 / 91$, estabeleceu que os recursos para o respectivo financiamento serão oriundos do orçamento da União, dos Estados, do Distrito Federal, dos Municípios e das contribuições sociais.

No art. 11, caput, incisos e parágrafo único da Lei do PCSS "Plano de Custeio da Previdência Social", está definido que em âmbito federal a composição do orçamento da seguridade social será constituída pelas receitas da União, das contribuições sociais e de outras fontes. As contribuições sociais são constituídas por: a) empregador (inclusive o doméstico), a empresa e a entidade a ela equiparada na forma da lei, sobre: a receita ou faturamento e o lucro; a folha de salários e demais rendimentos do trabalho, pagos ou creditados a qualquer título, à pessoa física que lhe preste serviços, mesmo sem vínculo empregatício; b) trabalhador, sobre o salário de contribuição; demais segurados da Previdência Social, inclusive o importador de bens ou serviços do exterior ou legalmente equiparados (valor da contribuição); c) receita de concursos de prognósticos. Mas, como positivado no art. 154 da CRFB/88, a União, mediante lei complementar, poderá estabelecer outras fontes destinadas a manutenção ou expansão da Seguridade Social.

Segundo o art. 20 da Lei do PCSS, a contribuição previdenciária do empregado, inclusive o doméstico e o trabalhador avulso variam, não cumulativamente, entre as alíquotas: $8 \%, 9 \%$ e $11 \%$ sobre o salário de contribuição mensal. Já, no art. 22 da citada Lei 8.212/91, encontra-se positivado, que a empresa ou seus equiparados, estão obrigados ao pagamento do valor de $20 \%$ para o custeio da Seguridade Social, que incidirá sobre a totalidade da remuneração paga, devida ou creditada a qualquer título a seus segurados, empregados ou prestadores de serviço avulso. No caso das instituições financeiras, o valor mencionado será 
acrescido em 2,5\%, também direcionado ao custeio da Seguridade Social. Mas, ainda deverá ser recolhido para o custeio do SAT (1 a 3 ) \%, dependendo a atividade preponderante.

O art. $25, \S 1^{\circ}$ da Lei $n^{\circ} 8.212 / 91$, faculta ao segurado especial, contribuir na forma do art. 21 desta mesma lei. Já, o $\S 2^{\circ}$ do citado art. 25 da Lei do PCSS, estabelece que a pessoa física especificada no art. 12, inciso V, alínea "a" do mesmo diploma legal, contribui obrigatoriamente, na forma do artigo 21 da Lei do PCSS.

\footnotetext{
A permissiva legal de contribuir da mesma forma que o segurado facultativo, não tira de forma alguma, a condição de segurado obrigatório do RGPS do segurado especial, constituindo-se, apenas, em uma vantagem legal de contribuir com as mesmas alíquotas do segurado facultativo ou do contribuinte individual, não alterando o seu enquadramento previdenciário. (KERTZMAN, 2013, p. 190).
}

Já, em conformidade com o $§ 13$ do referido art. 25 da Lei do PCSS, o produtor rural, pessoa física, poderá optar por contribuir conforme previsão do caput deste artigo ou na forma dos incisos I e II do caput do art. 22 da Lei do PCSS.

Desta forma, a contribuição do empregador rural, pessoa física, consiste em uma alíquota de contribuição em 1,2 \% sobre a receita bruta da comercialização da produção rural e ainda acrescenta a esse montante, $0,1 \%$ para o custeio do SAT/GILRAT, totalizando 1,3\% sobre o total bruto da venda da produção rural. Ou opcionalmente, segundo as condições da empresa, prevista no supracitado art. 22 da Lei do PCSS.

\subsection{Contribuição para custeio do SAT/GILRAT}

A alíquota para o SAT "seguro de acidentes do trabalho" é aferido pelo grau de risco desenvolvido em cada empresa, individualizada pelo seu CNPJ "Cadastro Nacional da Pessoa Jurídica" ou pelo grau de risco da atividade preponderante quando houver só um registro. Assim, os valores de contribuição das empresas para o custeio do SAT/GILRAT "seguro de acidentes do trabalho pelo grau de incidência de incapacidade laborativa decorrente dos riscos ambientais do trabalho" estão estabelecidos no inciso II, do citado art. 22 da Lei do PCSS e no art. 202 do Decreto ${ }^{\circ}$ 3.048/99.

O custeio do SAT/GILRAT será de: $1 \%$ para as empresas em que o risco da ocorrência de acidente do trabalho na atividade preponderante seja considerado leve; $2 \%$ para as empresas, cuja atividade preponderante, o risco da ocorrência de acidente do trabalho seja considerado médio; $3 \%$ para as empresas, cuja atividade preponderante - previstas no anexo $\mathrm{V}$ 
do RPS -, o risco da ocorrência de acidente do trabalho seja considerado grave. Conforme infracitado, a atividade preponderante estará vinculada ao número de trabalhadores expostos ao maior grau de risco, excluindo as atividades meio.

\begin{abstract}
Considera-se preponderante a atividade econômica que ocupa, na empresa, o maior número de segurados empregados e trabalhadores avulso, observado que: a) apurado na empresa ou no órgão do poder público, o mesmo número de segurados empregados e trabalhadores avulsos em atividades econômicas distintas, considerarse-á como preponderante aquela que corresponder ao maior grau de risco; b) não serão consideradas os segurados empregados que prestam serviços em atividademeio, para a apuração do grau de risco, assim entendidas aquelas que auxiliam ou complementam indistintamente as diversas atividades econômicas da empresa, tais como serviços de administração geral, recepção, faturamento, cobrança, contabilidade, vigilância, dentre outros. (DE CASTRO; LAZZARI, 2016, p. 267).
\end{abstract}

Nota-se que, a relação das referidas atividades preponderantes deverá ser elaborada pela empresa com base no CNAE "Classificação Nacional de Atividades Econômicas", consignadas no anexo V do RPS. Entretanto o STJ "Superior Tribunal Justiça", após diversos questionamentos sobre o enquadramento da atividade preponderante, editou a Súmula $\mathrm{n}^{\circ} 351$. Mesmo assim, o retrocitado enquadramento ainda motivou vários litígios, pacificado pelo STF “Supremo Tribunal Federal”, no julgamento do Ag. Reg. "Agravo Regimental” em RE "Recurso Extraordinário" n 650.696/PR, DJe, 14/11/2011, relatoria do Ministro Celso de Mello, que decidiu pela validade das normas. (BRASIL, STF, ARE 650.696/PR., 2017).

A empresa deverá informar mensalmente, utilizando a GFIP "guia de recolhimento do fundo de garantia do tempo de serviço e informações à Previdência Social", a alíquota referente ao grau de risco sobre as respectivas atividades preponderantes do estabelecimento, embasado no CNAE, previsto no anexo V do Regulamento da Previdência Social.

\title{
3.5 Contribuição do FAP/GILRAT
}

A Lei $\mathrm{n}^{\circ} 10.666 / 03$, regulamentada pelo Decreto $\mathrm{n}^{\circ} 6.042 / 07$, inseriu o art. 202-A ao RPS, criando o FAP "fator acidentário de prevenção", possibilitando a redução de até $50 \%$ ou acréscimo de até $100 \%$ da alíquota de contribuição do SAT/GILRAT. Para isso, utilizar-se-á um multiplicador com arredondamento na quarta casa decimal, varável de 0,5000 (meio) a 2,0000 (dois) sobre a retrocitada contribuição. “O FAP permite a diminuição da tributação para as empresas que diminuírem os riscos de acidentes de trabalho no ambiente laboral. $\mathrm{O}$ 
desempenho da empresa na diminuição dos acidentes de trabalho acabará ajustando a tributação para um pagamento maior ou menor. " (DALVI; DALVI, 2015, p. 671).

Os Ministérios do Trabalho e da Previdência Social, publicarão anualmente no Diário Oficial da União a relação dos percentuais de frequência, gravidade e custo da subclasse da CNAE, divulgando na internet o FAP de cada empresa. Para aquelas empresas, constituídas após janeiro de 2007, o FAP será calculado a partir do ano seguinte, após completar um biênio de constituição. (DE CASTRO; LAZZARI, 2016, p. 268-270). Enquanto a empresa não possuir o FAP, esta deverá informar os dados com o multiplicador igual a 1,0000 (um), utilizando-se 4 (quatro) algarismos após a vírgula. Para calcular a frequência, gravidade e custo para a definiçãa do FAP de cada empresa, utilizar-se-á os dados das CAT “comunicações de acidente do trabalho" registradas na Previdência Social, bem como os respectivos registros dos benefícios de natureza acidentária, atribuídos ao CNPJ que o trabalhador estiver vinculado. No caso do trabalhador avulso, o benefício será considerado para a empresa que o mesmo presta serviços.

Já, as empresas que apresentarem uma taxa média de rotatividade anual dos empregados, superior a $75 \%$ (excluído desse cálculo do simples acréscimo ou redução do quadro de funcionários) e as empresas que apresentarem casos de morte ou invalidez permanente, ficarão impedidas de receber o FAP inferior a 1,0000 (um). Entretanto, estas empresas poderão se redimir e eliminar esse impedimento, caso comprovarem aos sindicatos (patronal e dos trabalhadores) terem investido em recursos humanos e materiais que possibilite a melhoria da segurança do trabalho. (DE CASTRO; LAZZARI, 2016, p. 271).

Essa metodologia que possibilita modular o FAP, flexibilizando o tributo SAT/GILRAT "seguro de acidente do trabalho sobre o grau de incidência de incapacidade laborativa decorrente dos (RAT) "riscos ambientais do trabalho", tem previsão na Lei Ordinária ${ }^{\circ} 10.666 / 03$ e no art. 201-A, $\S 4^{\circ}$ e 202 do RPS. A referida alíquota é definida pelo CNPS “Conselho Nacional de Previdência Social”.

Conforme previsão dos artigos 146 e 146-A, ambos da CRFB/88, somente por lei complementar será possível criar, extinguir ou flexibilizar tributos. A modulação do RAT pelo FAP, ainda não está plenamente pacificada, tendo, inclusive a sua constitucionalidade questionada junto ao STF. A retrocitada modulação tem previsão em lei ordinária e em ato normativo infralegal, assim sendo, poderá ter a sua constitucionalidade questionada junto ao Poder Judiciário. 
A ABERC “Associação Brasileira das Empresas de Refeições Coletivas” através da ADI "ação direta de inconstitucionalidade" $\mathrm{n}^{\circ} 4.660$, questionou a referida modulação prevista na Lei Ordinária $n^{\circ} 10.666 / 03$ e no Decreto $n^{\circ} 3.048 / 99$-, porém, ainda está aguardando julgamento do STF. Mas, o mencionado Tribunal, já aceitou a existência de repercussão geral no Recurso Extraordinário n ${ }^{\circ}$ 684.261/PR que discute sobre a legalidade da fixação da alíquota tributária pelo CNPS. (DE CASTRO; LAZZARI, 2016, p. 275).

Outros estudiosos do Direito Previdenciário e Tributário, também questionam esta modulação do RAT pelo FAP. Segundo Marisa Ferreira dos Santos (2012, p. 42), por se tratar de contribuição nova, a contribuição do SAT deveria ser instruída por LC "lei complementar" e, por se trata de imposto de obrigação, a modalidade normativa de definição de atividade preponderante, deveria transcorrer por lei e não decreto. A classificação das atividades para fins do grau de risco também é matéria reservada à lei. Razão pela qual, o RPS infringiu o princípio da legalidade nestes dois dispositivos elencados. Conforme exposto, em detrimento do descumprimento de princípios constitucionais que estipulam as regras para a criação, supressão e flexibilização de tributos, a modulação do FAP, ainda gera conflitos e litígios jurídicos.

\subsection{Caracterização e direitos decorrentes do acidente de trabalho}

Para caracterização do acidente do trabalho, a empresa deve comunicar a sua ocorrência junto ao Previdência Social, fornecendo uma cópia ao acidentado - ou a seus dependentes - e outra ao sindicato da categoria. Nos termos do art. 21-A caput da Lei ${ }^{\circ}$ 8.213/91, a perícia médica do INSS “Instituto Nacional do Seguro Social” considerará a natureza acidentária, quando constatar a ocorrência de NTEP "nexo técnico epidemiológico previdenciário" entre o trabalho e o agravo, decorrente da atividade da empresa ou do trabalho doméstico e a entidade mórbida motivadora da incapacidade especificada na CID “classificação internacional de doenças" e no RPS. Porém, os $\S \S 1^{\circ}$ e $2^{\circ}$, do supracitado artigo, determinam, respectivamente, que a perícia médica do INSS não considerará caracterizada a natureza acidentária quando demonstrado a inexistência do NTEP, mas, tanto a empresa quanto o empregador doméstico poderão requerer a não aplicação do NTEP. Porém, caberá recurso administrativo da empresa, do empregador doméstico ou do segurado, ao Conselho de Recursos da Previdência Social e terá efeito suspensivo. 
Conforme determinação do art. $22, \S 1^{\circ}$, caput da Lei dos PBPS, a CAT deverá ser enviada pela empresa ou empregador doméstico à Previdência Social, até o primeiro dia útil subsequente ao acidente do trabalho e, no caso de redundar em morte do segurado, a referida comunicação, deve ocorrer imediatamente. Nos casos de a empresa ou empregador doméstico não providenciar a CAT conforme determina a lei, incidirá multa ao infrator (exceto na hipótese prevista no retrocitado caput do art. 21-A). Mas é facultado no $\S 2^{\circ}$ do citado artigo, que a respectiva comunicação seja efetuada extemporaneamente, pelo próprio acidentado, por seus dependentes, pela entidade sindical competente, pelo médico que assistiu o acidentado ou por qualquer autoridade pública.

Segundo o AEPS/16 “Anuário Estatístico da Previdência Social do ano de 2016” (2018, p. 561), último anuário disponibilizado, os acidentes com CAT registrada, corresponde ao número de acidentes onde a CAT foi cadastrada no INSS. Entretanto, não são contabilizados o reinício de tratamento ou afastamento por agravamento de lesão de acidente do trabalho ou doença do trabalho já comunicados ao INSS. Os acidentes sem CAT registrada, corresponde ao número de acidentes cuja CAT não foi cadastrada no INSS. O acidente é identificado por meio de um dos documentos: NTEP ou NTDEAT "nexo técnico por doença equiparada a acidente do trabalho". A identificação é feita pela nova forma de concessão dos benefícios acidentários.

Os acidentes são distribuídos em: a) acidentes típicos: são os acidentes decorrentes da característica da atividade profissional desempenhada pelo acidentado; b) acidentes de trajeto: são os acidentes ocorridos no trajeto entre a residência e o local de trabalho do segurado e vice-versa; c) acidentes devidos à doença do trabalho: são os acidentes ocasionados por qualquer tipo de doença profissional peculiar a determinado ramo de atividade constante na tabela da Previdência Social; d) acidentes liquidados que corresponde ao número de acidentes cujos processos foram encerrados administrativamente pelo INSS, depois de completado o tratamento e indenizadas as sequelas. (AEPS/16, 2018, p. 561).

Já, a assistência médica corresponde aos segurados que receberam apenas os atendimentos médicos para sua recuperação para o exercício da atividade laborativa. A incapacidade temporária, se refere aos segurados que ficaram temporariamente incapacitados para o exercício de sua atividade laborativa em função de acidente ou doença do trabalho. Conforme infracitado, não se exige carência para o auxílio-acidente. 
Conforme o art. 26 da Lei $\mathrm{n}^{\circ} 8.213 / 91$, caput e inciso I e II, independe de carência para a concessão de pensão por morte; auxílio-reclusão; salário família e auxílio acidente; auxílio doença e aposentadoria por invalidez nos casos de acidente por qualquer natureza ou causa e, de doença profissional ou do trabalho. Também independem de carência para aqueles que, após filiarem-se ao RGPS, foram acometidos por alguma doença e afecções listadas pelo Ministério da Saúde ou pela Previdência Social.

Desta maneira, como a Medida Provisória nº 664 de 30 de dezembro de 2014, que previa o prazo de 30 dias de afastamento do trabalhador para transferir do empregador para o INSS a responsabilidade do pagamento do benefício auxílio-doença acidentário -, com a promulgação do CPC/15, foi convertida em lei. E o CPC/15 é silente quando a esse prazo. Em conformidade com os art. 60 e 61 da lei no 8.213/91, o referido prazo será de 15 dias. Com o mesmo entendimento, a Previdência Social estabelece, conforme consignado no AEPS/16 (2018, p. 561), que a durante os primeiros 15 dias consecutivos ao do afastamento da atividade, caberá à empresa pagar ao segurado empregado o seu salário de forma integral, após este período, o segurado deverá ser encaminhado à respectiva perícia médica da Previdência Social para requerimento do auxílio doença acidentário. No caso de trabalhador avulso e segurado especial, o auxílio doença acidentário é pago a partir da data do acidente.

Assim, o regramento para definição do dia a ser considerado como data de início do acidente do trabalho em decorrência da doença profissional ou do trabalho, está positivado no art. 23 da Lei dos PBPS. Considerar-se-á, a data de início da incapacidade laborativa para exercício da atividade habitual desempenhada pelo segurado, ou o dia do afastamento compulsório, ou o dia em que for realizado o diagnóstico, predominando o que ocorrer primeiramente. A definição exata desta data é importante, principalmente, quando se tratar de benefícios cumulativos.

O auxílio doença, conforme disciplinado no art. 59 da Lei n ${ }^{\circ} 8.213 / 91$, será devido ao trabalhador segurado que, havendo cumprido, o período de carência exigido nesta lei (como visto, para o auxílio doença acidentário não há carência), ficar incapacitado para o seu trabalho ou para a sua atividade habitual por mais de 15 (quinze) dias consecutivos.

Segundo o art. 60, $\S \S 8^{\circ}, 9^{\circ}, 10$ e 11 da Lei ${ }^{\circ} 8.213 / 91$ (redação dada pela Lei $\mathrm{n}^{\circ}$ 13.457/17), na concessão ou revalidação do auxílio-doença, judicial ou administrativo, sempre que possível, deverá fixar prazo estimado para duração do benefício. Na ausência de fixação do prazo referido, o benefício cessará após o prazo de 120 (cento e vinte) dias, 
contados da concessão ou revalidação do auxílio-doença, exceto se o beneficiário requerer a revalidação nos moldes do art. 62 desta lei (processo de reabilitação profissional). $\mathrm{O}$ beneficiário do auxílio-doença, concedido administrativamente ou judicialmente, poderá ser convocado a qualquer momento para avaliação das condições que ensejaram sua concessão ou manutenção, observado o art. 101 da referida lei. Porém, caso não concorde com a perícia, caberá recurso ao Conselho de Recursos do Seguro Social no prazo máximo de 30 (trinta).

Já, no art. 61 da Lei dos PBPS, encontra-se estabelecido que o auxílio doença, inclusive o decorrente do acidente do trabalho, consistirá numa renda mensal correspondente a 91\% do salário benefício, que não deverá ser inferior ao salário mínimo, nem superior ao do limite máximo do salário de contribuição.

Porém, os segurados, vítimas dos acidentes do trabalho, poderão ficar permanentemente incapacitados para o exercício laboral. Esta incapacidade, poderá ser parcial ou total. Entende-se por incapacidade permanente parcial, o fato do acidentado em exercício laboral, após o devido tratamento psicofísico-social, apresentar sequela definitiva que implique em redução da capacidade. Esta informação é obtida a partir da concessão do benefício denominado como auxílio acidente. Já a incapacidade permanente total ocorre quando o acidentado em exercício laboral apresentar incapacidade permanente e total para o exercício de qualquer atividade laborativa. Esta informação relativa à incapacidade permanente é levantada a partir da concessão do benefício da aposentadoria por invalidez derivada do acidente do trabalho. (AEPS/16, 2018, p. 562).

A Súmula 507 do STJ "Superior Tribunal de Justiça" somente admite a acumulação do auxílio acidente com aposentadoria especial, quando a lesão incapacitante e a aposentadoria forem anteriores a 11 de novembro de 1997. A data de início se dará em conformidade com o citado art. 23 da Lei dos PBPS. Como visto, hodiernamente, não se admite a acumulação de benefícios previdenciários. Está positivado no art. 86, caput da Lei ${ }^{\circ}$ 8.213/91 que o auxílio-acidente será concedido, como indenização ao segurado - após consolidação das lesões decorrentes de acidente de qualquer natureza - quando resultar sequelas que impliquem redução da capacidade para o trabalho que habitualmente exercia.

Os $\S \S 1^{\circ}$ ao $4^{\circ}$ do aludido artigo 86 da Lei dos PBPS, estabelecem que o auxílio acidente mensal corresponderá a 50\% do salário-de-benefício e será devido até à véspera do início de qualquer aposentadoria ou até a data do óbito do segurado. O auxílio-acidente será devido a partir do dia seguinte ao da cessação do auxílio-doença, independentemente de 
qualquer remuneração ou rendimento auferido pelo acidentado, vedada sua acumulação com qualquer aposentadoria. Porém, a perda da audição, em qualquer grau, somente proporcionará a concessão do auxílio acidente, quando admitido o nexo causal entre o trabalho e a perda auditiva e a sequela resultar, comprovadamente, na perda ou redução da capacidade para o trabalho habitual.

Nos termos do art. 118 da Lei $\mathrm{n}^{\circ}$ 8.213/91, o segurado que sofreu acidente de trabalho tem garantia pelo prazo de 12 (doze) meses, assegurando a manutenção do seu contrato de trabalho na empresa, após a cessação do auxílio doença acidentário, independentemente de percepção de auxílio acidente. O item III, da Súmula 378 do TST, estabelece que nos contratos por tempo determinado, o empregado vítima de acidente de trabalho (art. 118 da Lei dos PBPS) também goza da garantia provisória de emprego.

Todavia, o pagamento do auxílio acidente pelo INSS, não exclui o direito à indenização por danos materiais e morais decorrentes do respectivo acidente do trabalho. Como observa Sebastião Geraldo de Oliveira (2014, p. 85), o art. 121 da Lei dos PBPS, assegura que o pagamento pelo INSS das prestações (benefício) por acidente do trabalho, não exclui a responsabilidade civil da empresa ou de outrem. A responsabilidade civil do empregador, decorrente do acidente do trabalho está pacificada, especialmente diante do peso e da dimensão dos preceitos constitucionais previstos no art. $7^{\circ}$, inciso XXVIII da CRFB/88.

$\mathrm{O}$ direito ao recebimento do benefício previdenciário decorrente do acidente do trabalho, independe de culpa do empregador - responsabilidade objetiva. Segundo Sérgio Cavalieri Filho (2014, p. 235), excepcionalmente, nas hipóteses do art. 932 do CC/02 uma pessoa pode vir a responder pelo fato de outrem, teremos a responsabilidade objetiva indireta.

Como determinam os artigos: 927, parágrafo único, 932, inciso III e 933, todos do CC/02, o empregador, ainda que não tenha culpa, independente da natureza jurídica do vínculo, responde pelos atos praticados por seus empregados ou prestadores de serviço, devido a culpa in eligendo. O benefício previdenciário não inibe o direito de o acidentado receber as reparações, inclusive de danos morais, decorrentes da responsabilidade civil.

Também será do empregador a responsabilidade pelas indenizações por dano material, moral ou estético decorrentes de lesões vinculadas à infortunística do trabalho, sem prejuízo do pagamento pelo INSS do seguro social, é claro. [...]. Tratando-se de dano material, a ordem jurídica exige a comprovação não apenas do fator deflagrador do dano, porém da própria materialidade desse dano (ou seja, as perdas materiais sofridas; as despesas feitas; as despesas que devem ser realizadas em decorrência do dano; os lucros cessantes em face da perda sofrida etc.). Isso é o deflui das regras dispostas no art. 949 e 950 do CC/2002, por exemplo. [...]. 
Esclareça-se que com relação a esse primeiro requisito - ocorrência do dano - que nas situações envolventes a acidente do trabalho, doenças ocupacionais e doenças profissionais o dano é considerado presumido, se não auto evidente. É que tal tipo de agressão a higidez física e psíquica do ser humano já traduz em si, uma lesão ao patrimônio moral, emocional, psíquico do indivíduo. $\mathrm{O}$ segundo requisito é o nexo casal. [...]. O terceiro requisito é, finalmente, a culpa do empresarial. [...]. A culpa obreira concorrente, entretanto, não tem o condão de excluir essa responsabilidade; mas pode, sem dúvida, atenuá-la, em conformidade com as circunstâncias do caso examinado. (DELGADO, 2012, p. 623-627).

Todavia com a edição da Lei 13.467/17 os danos morais sofreram contundente alteração, considerada inconstitucional pelo $\mathrm{EN} \mathrm{n}^{\circ} 18$ da $2^{\mathrm{a}} \mathrm{JDMPT}$.

\begin{abstract}
Aplicação exclusiva dos novos dispositivos do título II-A da CLT à reparação de danos extrapatrimoniais decorrentes das relações de trabalho: inconstitucionalidade. A esfera moral das pessoas humanas é conteúdo do valor dignidade humana (art. $1^{\circ}$, III, da $\mathrm{CF}$ ) e, como tal, não pode sofrer restrição à reparação ampla e integral quando violada, sendo dever do Estado a respectiva tutela na ocorrência de ilicitudes causadoras de danos extrapatrimoniais nas relações laborais. Devem ser aplicadas todas as normas existentes no ordenamento jurídico que possam imprimir, no caso concreto, a máxima efetividade constitucional ao princípio da dignidade da pessoa humana (art. $5^{\circ}, \mathrm{V}$ e X, da CF). A interpretação literal do art. 223-A da CLT resultaria em tratamento discriminatório injusto às pessoas inseridas na relação laboral, com inconstitucionalidade por ofensa aos artigos $1^{\circ}$, III; $3^{\circ}, \mathrm{IV} ; 5^{\circ}$, caput e incisos $\mathrm{V}$ e $\mathrm{X} \mathrm{e} 7^{\circ}$, caput, todos da Constituição Federal. (ANAMATRA, $2^{\mathrm{a}}$ JDMPT, 2017).
\end{abstract}

A inconstitucionalidade de determinados dispositivos do título II-A da CLT é evidente. Observa-se que, no art. 223-B (incluído pela Lei ${ }^{\circ}$ 13.467/17) mistura-se dano moral da pessoa natural com dano moral da pessoa jurídica, institutos bem diferentes. No art. 223-C (incluído pela Lei $n^{\circ}$ 13.467/17), criaram um rol dos direitos da personalidade, incompatível com os princípios constitucionais (deve ser entendidos como exemplificativo). No art. 223-E (incluído pela Lei $n^{\circ} 13.467 / 17$ ), violaram o princípio da alteridade e do risco da atividade e, consequentemente, a responsabilidade in eligendo, pois admitiu-se a responsabilidade solidária nos danos extrapatrimoniais. O art. 223-G (incluído pela Lei ${ }^{\circ}$ 13.467/17), estabeleceu parâmetros para quantificar financeiramente o dano moral. Não há como quantificar o dano à personalidade. Assim, caberá ao Poder Judiciário dirimir as controvérsias retrocitadas.

\title{
3.7 Situação dos acidentes do trabalho no brasil nos últimos anos
}


Os acidentes do trabalho no Brasil reduziram consideravelmente nos últimos anos. Mas, como demonstrado a seguir, os valores ainda são muito elevados, precisa-se reduzi-los a patamares bem menores. No ano de 2013, um total de 725.664 trabalhadores foram vitimados por acidentes do trabalho no Brasil. Deste montante, 563.704 acidentados, registraram a CAT no INSS e, 161.960 acidentados, não registraram a CAT no INSS. Os acidentes do trabalho no ano de 2013, subdividiram em: 434.339 acidentes típicos; 112.183 acidentes de trajeto e, 17.182 doenças de trabalho. (AEPS/15, 2017, p. 585).

O cotejamento dos valores computados em 2013, com os dados da Tabela 1, acidentes no Brasil de 2014 a 2016, constata-se a supracitada redução dos acidentes, mas, ratifica a preocupante afirmativa dos ainda elevados quantitativos de acidentes do trabalho no país.

TABELA 1 - Acidentes de trabalho no Brasil de 2014 a 2016

\begin{tabular}{lccc}
\hline \multicolumn{4}{c}{ Acidente do trabalho no Brasil } \\
\hline \multicolumn{1}{c}{ Quantidade de acidentes } & $\mathbf{2 0 1 4}$ & $\mathbf{2 0 1 5}$ & $\mathbf{2 0 1 6}$ \\
\hline Total com CAT registrada & 564.283 & 507.753 & 474.736 \\
Total de acidente típico & 430.454 & 385.646 & 354.064 \\
Total de acidente de trajeto & 116.230 & 106.721 & 108.150 \\
Total de doenças do trabalho & 17.599 & 15.386 & 12.502 \\
Total sem CAT registrada & 148.019 & 114.626 & 104.199 \\
Total geral & $\mathbf{7 1 2 . 3 0 2}$ & $\mathbf{6 2 2 . 3 7 9}$ & $\mathbf{5 7 8 . 9 3 5}$ \\
\hline
\end{tabular}

Fonte: Ministério da Fazenda et. al., AEPS/16 - seção IV, p. 593, 2018.

Conforme exposto, de 2013 para 2014, houve um decréscimo no número geral de acidentes de trabalho no Brasil, na ordem de 9,82 \%; já do ano de 2013 para 2015, o decréscimo foi de 14,2 \% e, do ano de 2013 para 2016, o decréscimo foi de 20,2 \%. Note-se que a redução dos acidentes do trabalho tem se mantido decrescente, porém em um patamar ainda elevado.

Durante o ano de 2016, foram registrados no INSS cerca de 578,9 mil acidentes do trabalho. Comparado com 2015, o número de acidentes de trabalho teve um decréscimo de 6,98\%. O total de acidentes registrados com CAT diminuiu em 6,5\% de 2015 para 2016. Do total de acidentes registrados com CAT, os acidentes típicos representaram 74,59\%; os de trajeto $22,78 \%$ e as doenças do trabalho $2,63 \%$. As pessoas do sexo masculino participaram com $69,49 \%$ e as pessoas do sexo feminino $30,50 \%$ nos acidentes típicos; $59,64 \%$ e $40,36 \%$ nos de trajeto; e 56,99\% e 42,99\% nas doenças do trabalho. Nos acidentes típicos e nos de trajeto, a faixa etária decenal com maior incidência de acidentes foi a constituída por pessoas de 25 a 34 anos 
com, respectivamente, $33,58 \%$ e $36,29 \%$ do total de acidentes registrados. Nas doenças de trabalho, a faixa de maior incidência foi a de 30 a 39 anos, com 34,23\% do total de acidentes registrados. [...]. Em 2016, o número de acidentes de trabalho liquidados foi de aproximadamente 595 mil acidentes, o que correspondeu a um decréscimo de 6,88\% em relação a 2015. A assistência médica teve um decréscimo de $4,99 \%$ e os óbitos diminuíram $11,04 \%$ em relação a 2015. As incapacidades temporárias diminuíram em 7,25\% e as incapacidades permanentes decresceram em $5,87 \%$ de 2015 para 2016. As principais consequências dos acidentes de trabalho liquidados foram as incapacidades temporárias com menos de 15 dias e com mais de 15 dias, cujas participações atingiram 52,50\% e 28,94\% do total, respectivamente. (AEPS/16, 2018, p. 564-565).

Como exposto, no cotejamento dos números de acidentes do trabalho do ano de 2016 com os de 2015, também se mostrou significativa, apresentou um decréscimo de 6,98 \% . Do total de acidentes registrados, os acidentes típicos foram os que mais ocorreram, registraram $74,59 \%$ do total; os de trajeto somaram $22,78 \%$ e as doenças do trabalho, apenas 2,63\%.

Todos os indicadores foram reduzidos em termos percentuais, os números totais de acidentes, os de acidentes liquidados, as incapacidades temporárias, as incapacidades permanentes, dentre outros. Porém, o que chama a atenção, são os óbitos, que diminuíram em $11,04 \%$, em relação ao ano de 2015.

\section{CONSIDERAÇÕES FINAIS}

A Lei $n^{\circ}$ 13.457/17, que alterou o art. 60 e outros da Lei 8.213/91 (Lei dos planos de benefícios da Previdência Social), compromete a segurança jurídica e o ato jurídico perfeito. Pois, ao instituir a possibilidade de fracionar e questionar, a qualquer momento, o auxíliodoença concedido sem vícios e de boa-fé pelo Poder Judiciário, além de desrespeitar a dignidade humana, também afronta a coisa julgada.

Entretanto, na análise dos dados estatísticos acidentários efetuada por esta pesquisa, ficou demonstrado que ocorreu uma considerável redução dos acidentes do trabalho no interregno de 2013 a 2016, não há como deixar de atribuir este resultado à uma legislação apropriada, aliada a efetividade dos profissionais que atuam na fiscalização e na segurança do trabalho. As questionadas alterações da CLT, advindas da Lei 13.467/17, podem comprometer as reduções dos acidentes, pois desordenaram muitos institutos da CLT, assim o horizonte é incerto. Pois, para alcançar uma incisiva redução dos referidos acidentes, deve-se incrementar a divulgação dos dados acidentários, visto que é imprescindível a conscientização dos empregadores e dos empregados sobre a importância da adoção de medidas de prevenção dos 
acidentes do trabalho. Também é indispensável dispor de uma adequada legislação, aliada às políticas públicas que valore a saúde física e psicológica dos trabalhadores.

Os acidentes do trabalho no Brasil, conforme citado alhures, têm decrescido de forma substancial, inclusive com relação aos óbitos decorrentes destes acidentes. Com isso, fica demonstrado que a legislação, até então, se apresenta eficaz tanto para redução dos mencionados acidentes quanto para preservar os direitos - das vítimas - segurados da previdência social brasileira. Todavia, aguarda-se com apreensão os novos dados estatísticos dos acidentes do ano de 2018, já, sob a égide da questionada Lei $\mathrm{n}^{\circ} 13.467 / 17$ - que reformou a CLT. Haja vista, que as supracitadas reduções dos acidentes e melhoria da segurança do trabalho podem ser comprometidas pelas alterações advindas da referida legislação ordinária.

\section{REFERÊNCIAS}

ANUÁRIO ESTATÍSTICO DA PREVIDÊNCIA SOCIAL. AEPS/16. Ministério da Fazenda et al. Arq. Microsoft Acrobat Reader, PDF, 2018. Brasília: MF/DATAPREV, 2018.

Disponível em: $\langle$ http://www.previdencia.gov.br/wp-content/uploads/2018/01/AEPS-016.pdf $>$. Acesso em: 02 fev. 2018.

ANUÁRIO ESTATÍSTICO DA PREVIDÊNCIA SOCIAL. AEPS/15. Ministério da Fazenda et al. Arq. Microsoft Acrobat Reader, PDF, 2017. Brasília: MF, 2017. Disponível em:< http://www.mtps.gov.br/dados-abertos/dados-da-previdencia/previdencia-social-einss/anuario-estatistico-da-previdencia-social-aeps>. Acesso em: 19 dez. 2017.

ASSOCIAÇÃO NACIONAL DOS MAGISTRADOS DA JUSTIÇA DO TRABALHO. $2^{a}$ Jornada de Direito Material e Processual do Trabalho. Enunciados aprovados - 2a JDMPT. Brasília, 9-10 out. 2017. Disponível em: <http://www.jornadanacional.com.br/listagemenunciados-aprovados-vis2.asp>. Acesso em: 14 nov. 2017.

BRASIL. Ag. Reg. em Recurso Extraordinário - ARE 650696 PR. Supremo Tribunal Federal Rel. Min. Celso Mello. Jus Brasil. Disponível em:

<http://www.jusbrasil.com.br/jurisprudencia/busca?q=Recurso+no+pertinente+improvido>. Acesso em: 30 dez. 2017.

BRASIL. NR-7. Programa de Controle Médico e Saúde Ocupacional- PCMSO. In: ATLAS, Equipe. (Org. e Sup.). Manuais de Legislação Atlas. Segurança e Medicina do Trabalho. 7. ed. São Paulo: Atlas, 2014.

CAVALIERI FILHO, Sérgio. Programa de Responsabilidade civil. 11. ed. São Paulo: Atlas, 2014.

DALVI, Fernando; DALVI, Luciano. Manual prático de rotinas trabalhistas e previdenciárias descomplicado. Campo Grande: Contemplar, 2015. 
DE CASTRO, Carlos Alberto Pereira; LAZZARI, João Batista. Manual do Direito Previdenciário. 19. ed. rev., atual. e ampl. Rio de Janeiro: Forense, 2016.

DELGADO, Maurício Godinho. Curso de Direito do Trabalho. 11. ed. São Paulo: LTr, 2012.

DE OLIVEIRA, Sebastião Geraldo. Indenizações por acidente do trabalho ou doença ocupacional. 8.ed. ver., ampl. e atual. São Paulo: LTr, 2014.

DOS SANTOS, Marisa Ferreira. Direito previdenciário. 8. ed. São Paulo: Saraiva, 2012.

IBRAHIM, Fábio Zambitte. Curso de Direito Previdenciário. 21. ed. Rio de janeiro: Impetus, 2015.

RODRIGUES, Deusmar José. Manual Temático de Direito Trabalhista. Leme: J. H. Mizuno, 2014.

SENA, Adriana Goulart. Indenização e perda da capacidade laborativa. In: RODRIGUES JUNIOR, Otavio Luiz; MAMEDE, Gladston; ROCHA, Maria Vital da. (Coord.).

Responsabilidade civil contemporânea: em homenagem a Sílvio de Salvo Venosa. São Paulo: Atlas, 2011.

KERTZMAN, Ivan. Curso prático de Direito Previdenciário. 10. ed. rev., ampl. e atual. Salvador: Jus Podivm, 2013. 